\title{
SUSTAINABLE TECHNOLOGIES FOR HEALTH EDUCATION IN LOW AND MIDDLE INCOME COUNTRIES
}

\author{
Elisa Ferrara $^{(a)}$, Silvana Dellepiane $^{(b)}$, Marco Frascio $^{(c)}$ \\ (a),(b) Dept. of Naval, Electrical, Electronics and Telecommunication Engineering (DITEN), University of Genoa, \\ Via all'Opera Pia, 11a, 16145 Genoa - Italy - \\ (c) Dept. of Surgery Sciences (DISC) University of Genoa, Largo R. Benzi, 816132 Genoa - Italy - \\ (a) elisa.ferrara@edu.unige.it, ${ }^{\text {(b) }}$ silvana.dellepiane@unige.it, ${ }^{(c)}$ mfrascio@unige.it
}

\begin{abstract}
Sustainable technologies and collaborative Learning Management Systems (LMS) are investigated according to the Sustainable Development Goals (SDGs), as possible ways to improve, towards distance learning systems, education and towards it, social empowerment and development. Web -based systems, customized for academic teaching in medicine and surgery field, could help the development of cooperation among universities as well as research empowerment and exchange, useful for all the involved stakeholders. Different uses and approaches to the technological solution allow different participants to model and interact with the project despite also difficulties and environmental gaps that could occur in some LMIC.
\end{abstract}

Keywords: Sustainable technologies, LMS, mHealth, medicine and surgery education.

\section{INTRODUCTION}

Low and Medium Income Countries (LMIC) are here defined as the World Bank does, under a financial point of view. This means that in the present work we should consider Low-Income economies as those with a GNI per capita of $\$ 1,005$ or less; Middle-Income countries (MICs) nations with a per-capita gross national income in 2016 between $\$ 1,005$ and $\$ 12,615$. Low-Income and Middle-Income economies are collectively referred to as developing economies. [1]

Among the LMIC it is countable the greatest concentration of criticality in terms of poverty, disease and low levels of education and professional education, given mostly by lack of social security as well as a presence of low level political actions and policies.

In order to meet the seventeen Sustainable Development Goals (SDGs) - which range from halving extreme poverty rates to halting the spread of HIV/AIDS and providing universal primary education, all by the target date of 2030 - a blueprint agreed by all the world's countries and all the world's leading development institutions has been exploited. The goals this paper will partially address are goal 3 and 4 .

SDG number 3 "Ensure healthy lives and promote wellbeing for all at all ages" seeks to ensure health and wellbeing for all, at every stage of life.

The Goal addresses all major health priorities, including:
- $\quad$ reproductive, maternal and child health;

- environmental diseases;

- universal health coverage;

- access for all to safe, effective, quality and affordable medicines and vaccines.

It pushes empowerment in research and development, increased health financing, and strengthened capacity of all countries in health risk reduction and management.

SDG Number 4 "Ensure inclusive and equitable quality education and promote lifelong learning opportunities for all", aims to help in achieving inclusive and equitable quality education for all will require increasing efforts, especially in sub-Saharan Africa and Southern Asia and for vulnerable populations, including persons with disabilities, indigenous people, refugee children and poor children in rural areas. [1]

According to the World Health Organization data, in the world there is a shortage of health care workers for a total amount of 7.2 million people [2]. This is supposed to grow up to 12.8 million in 2035.

This is evident especially for LMIC and, according to the Sustainable Development Goals, promotion of both high education and health is a concrete target to join, that Information and Communications Technology ICT use can easily improve.

In many countries a big effort is made in order to increase health care workforce and to make a coherent distribution in underserved areas but it is a work in progress situation. In face of severe faculty shortages in resources constrained countries, medical schools look to e-learning systems for improved access to medical education and in this work we will try to analyse some possibilities

\section{DEFINITION AND TARGET}

In order to improve the quality of education and increase the pool of people who can benefit of it, priority solution should be given to "brain drain" phaenomenon [4]; due to lack of adequate training, people coming from LMICs decide to study in other countries mostly in Europe. After their graduation, they often refuse to return to the land of origin due to an absence of solid social guarantees and the prospect of a salary inadequate to their preparation. In the education of workers in medical area can be strongly and locally supported by the improvement of ICT based solutions in the educational and health care environments. 
In such particular contexts like LMICs are, the consideration of infrastructures and technologies to be chosen is fundamental. [5]

The definition of sustainability that has been considered in this work is "the feature of a process that can be maintained at a certain level indefinitely "[3]

A technological system is sustainable when it offers different is the possibility of training locally all the people involved as well as the possibility to find locally al the technical, the simplicity and ease of use and maintenance.

African Countries started a real process of empowerment and recovery already in the last 20 years [6].

The development of communication on a global scale has given rise to the ICT, which is realized through a wide range of infrastructures, services, content and applications, from traditional telecommunications to the Internet, by mass media (such as television) and individual communication media (such as telephone and the computer), to advanced applications of telematics systems. [7][8][9]

Along with this, from the technological point of view, an interesting phenomenon has started to take place, that is the spread of mobile communication and technologies [10].

According to the International Telecommunication Union there are now close to 5 billion mobile phone subscriptions in the world, with over $85 \%$ of the world's population now covered by a commercial wireless signal [11].

Communication development and the globalization phenomenon involved also the spread of the diffusion on ICT through an extensive variety of infrastructures, offerings, content material and applications, from conventional telecommunications to the internet, via mass media (which includes television) and personal communication media and tools like the mobile and smartphones and laptops. [7][8][9]

Together with this, from the technological point of view, a thrilling phenomenon has started, this is the unfold of cellular and mobile communication and technologies [10].

In line with the International telecommunication Union at the moment there are close to five billion cellular smartphone in the world, and more than $85 \%$ of the global surface is now covered by a wireless signal [11]. The penetration of mobile phone networks in many lowand middle-income countries surpasses other infrastructure such as paved roads and electricity, and dwarfs fixed Internet deployment [10]. The growing sophistication of these networks - offering higher and higher speeds of data transmission alongside cheaper and more powerful handsets - are transforming the way health services and information are accessed, delivered, and managed. With increased accessibility comes the possibility of greater personalization and citizen-focused public health and medical care [12] [13].

ICT has been largely introduced in medicine, both in education [14] and in clinical practice as in surgery and medicine [15]
The unprecedented spread of mobile technologies as well as advancements in their innovative application to address health priorities has evolved into a new field of eHealth, known as mHealth.

mHealth is a component of eHealth. To date, no standardized definition of mHealth has been established. The main definition can consider mHealth or mobile health as medical and public health practice supported by mobile devices, such as mobile phones, patient monitoring devices, personal digital assistants (PDAs), and other wireless devices.

mHealth may involve the use on a mobile phone's core utility of voice and short messaging service (SMS) as well as more complex functionalities and applications including general packet radio service (GPRS), third and fourth generation mobile telecommunications $(3 \mathrm{G}$ and 4G systems), global positioning system (GPS), and Bluetooth technology[13].

In such an environment, e-learning provides the opportunity to extend new medical courses and reach distant students from the main university centres.

Along with e learning and cooperative learning methods, in such an important field like health education, there are also simulation and remote monitoring systems that can help in improving the service, especially in geographical remote areas and countries.

We will explore these opportunities in the next paragraphs.

\section{APPLICATION}

We can define different types of e-learning, always considering all the forms of electronically-mediated teaching [8]

It is teaching and learning through ICT inside the classroom or outside. In some cases it could be also included the use of ICT as telemedicine system, allowing students to interact on a real case study session [14].

The e-Learning systems refer to the use of internet technologies and bring to a real collaborative and responsible interaction of the learners who can have a control over content, tailoring their experience in order to meet their personal learning objectives. Individuals are assumed to learn better when they discover things by themselves and when they control the pace of learning. Therefore, it is natural to expect that self-directed, interactive learning would improve learning outcome.

The most common system of e-learning are distance learning systems and computer assisted instruction; both of them have the purpose to increase accessibility to information through the ease of distribution and the standardization of content [15].

E-Learning therefore has become one of the fastestmoving trends [16] and aims to provide a configurable infrastructure that integrates learning material, tools, and services into a single solution to create and deliver training or educational content quickly, effectively, and economically.

It is possible to state that e-Learning is a process that helps in develop, manage, deliver and standardize knowledge contents. 
In order to perform a good service through an e learning system we should consider some aspects and components of the entire process of management and release of the content, within the system itself.

Contents: it is possible to define as content all the instructional and digital learning objects, and the digital materials assembled around specific learning lessons or modules.

Management: all the administrative functions (storing, indexing etc.) to make content available to students; this phase could be lead through portals, repositories and libraries;

In this phase the introduction of Learning Management Systems (LMS) could become an effective improvement, since they can help in simplifying and automate teacher tasks, track students' achievement of skills and they finally are repositories available $24 \mathrm{~h} / 7$. [13]

Linked to this the transport of content material in synchronous and asynchronous manner is an instantaneous effect.

The synchronous mode gives the possibility of an actual time delivery, all novices speak with other inexperienced persons and get hold of the lesson concurrently.

With the asynchronous mode, transmission and receipt aren't simultaneous and freshmen are responsible of their very own training and learning. Communication among instructors and newbies is supplied with the aid of emails or other technologies but not in actual time.

The importance of collaboration within distance getting to know methods, particularly in asynchronous systems has been highlighted already in literature [7]; [8]; [9]; [10] .LMS allow students to communicate with their peers and tutors thus empowering them to socialise and learn together also through remote technological systems helping in participating to their own education.

One example can be the Aquilone Project, ruled by University of Genova; a web-based system, customized for an academic year proposal in medicine and surgery field, has been settled up, in order to help the development of cooperation among universities and research empowerment and exchange: a University in Cameroon has been involved [17][18].

The system has been evaluated useful for both entities and their stakeholders. Different uses and approaches to the technological solution allowed different participants to model and interact with the project despite difficulties and environmental gabs that could occur in some territories for example in Sub-Saharan countries.

Another way to improve a good education in health care studies, is the simulation serious game.

An innovative approach is the application of serious games concepts in supporting and renew the educational processes in Health Care. One of the best way is application of new models of virtual humans to be used as patients in a distributed simulation game together with students to teach them concepts related to the continuous care of patients; the aim could be to create a strong relationship between medical doctor students and their set of personal virtual patients, driven by intelligent agents.
By following this approach, it is possible to reproduce the patient life cycles and teach students on subjects such as pathology evolution, preventive actions, symptoms identification and human relationships. MARIA (Model for Advanced and Realistic patient simulation driven by Intelligent Agents) is one example of solution developed by University of Genova and it has to be regarded as an innovation in the educational programs for health students enabled by new technologies [21].

\section{EXPLORING COOPERATIVE AND SUSTAINABLE EDUCATION: TECHNICAL APPROACH}

According to the cooperative and sustainable approach to education, many different approaches can be explored; this may help in a collaborative maintenance of the software and of the learning platform itself, giving to the learners the opportunity to adapt and promote their personal knowledge and through an open source, modular, and configurable software solution according to specific needs. A large community that gives information for maintenance and possible evolutions to the educational process of students and users and the participation itself, is a way to stimulate people to care about their own education. A favourable approach is to refer to an environment for the knowledge management, based on the ideology according to which each constructionist learning would be facilitated by the production of tangible objects [17]

The constructionist ideology, from which was born the US "No Child Left Behind Act of 2001" [14] is highlighted by various aspects of development, such as the ability to insert and comment data tables or wiki students, or to deliver tasks over the Internet. It offers a range of modules that enable tutors to create online courses and it tries to empower and address the need for pedagogical support, promoting the definition of constructionist learning, where a student learns from his or her own experiences, giving shape to student-centred learning environment.

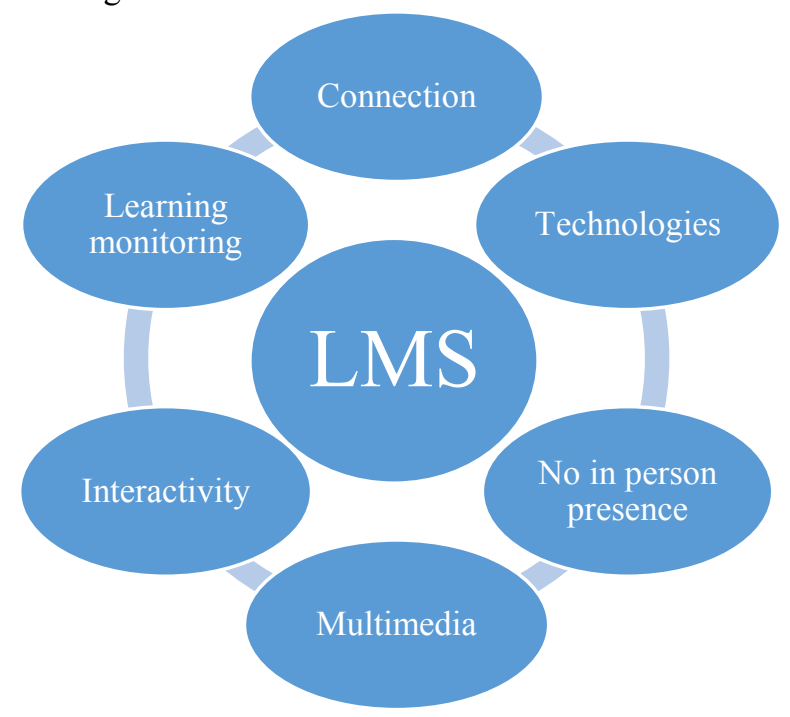

Figure 1: LMS elements 
Although e-Learning synchronous systems are preferred, in case of lack of connection or electricity distribution, the asynchronous use and distance learning methods are more reliable and convenient. [18]

The cooperative and sustainable education technique leaves the instructor the possibility to manipulate its personal route, directing it to the success of effects and to manipulate it in a far off manner.

What can be empowered from the pedagogic point of view is particularly noted as follows:

- Provision of lectures within the lecture room adaptable to specific needs of Internet access.

- Teaching materials (ppt and pdf) and video on hand at any time and downloadable

- Availability of extra teaching materials and / or guidelines of deepening: articles, references and other possible sources.

- Forum / chat for interaction with teachers and ask for explanation.

- Archive established and indexed upgradeable, to look for subjects.

- Exams control: the local tutor/teacher learns how to observe, evaluate and corrects the texts.

- Video conference when useful.

These tools can genuinely empower sharing knowledge and help the circulation of people and educational and research topics also from far underdeveloped and deprived areas of the world, empowering the health care service and schooling also in case of bad telecommunications and thanks to low price hardware systems and infrastructures [13].

\section{CONCLUSIONS}

Use of technologies and LMS is awarded as one of the most effective solutions to empowerment of medical education in LMICs contexts.

In fact, the possibility to access different applications and contents through dedicated applications will allow people completing their career in their local universities, to give their contribution to the society that took care of them since the beginning of their education and to establish a connection with their countries and their people.

Empowering these platforms and apps and customising them according to new advices and needs, helps also in spreading in many fields, and towards it, many other countries and educational systems could benefit of a high quality service at a cheap price. Moreover, digital divide problems that could occur in some areas of the world could be overlapped thanks to the use of open sources but consolidated technologies, able to adapt to different territories and circumstances.

The objective is raising awareness and towards it social empowerment and subsequent policy development.

It will be easier and cheaper for the international community to meet the seventeen Sustainable Development Goals (SDGs), especially those linked to education and health care spread.
The UN reports [20] reveal that SDG number 3 "Ensure healthy lives and promote well-being for all at all ages" already achieved good empowerment, one of the most important achievements is in Global maternal mortality ratio that felt by $37 \% .2000$ to 2015 .

SDG number 4 "Ensure inclusive and equitable quality education and promote lifelong learning opportunities for all" instead, faces some difficulties that can be underlined also as follows.

In 2014, 2 out of 3 children worldwide participated in pre-primary or primary education in the year prior to the official entrance age for primary school, compared to only 4 in 10 children in the poorest countries.

Despite considerable gains in primary school enrolment between 2000 and 2014, $9 \%$ of primary-school-aged children worldwide were out of school in 2014, with little progress since 2008 .

Surveys undertaken between 2007 and 2015 in selected countries show that children and adolescents from the richest $20 \%$ of households achieved greater proficiency in reading than those from the poorest $20 \%$ of households, and urban children scored higher in reading than rural children. Data for 2011 indicate that only about one quarter of schools in sub-Saharan Africa had electricity, less than half had access to drinking water, and only $69 \%$ had toilets (with many lacking separate sanitation facilities for girls and boys).

Looking at a transversal SDG 7 "Build resilient infrastructure, promote inclusive and sustainable industrialization and foster innovation" there are encouraging and high level results:

- Global investment in research and development increased at an average annual rate of $4.5 \%$ between 2000 and 2014. It reached 1.8 trillion US dollars (purchasing power parity) in 2014 1.7 per cent of global GDP.

- Coverage by a mobile cellular signal has become almost universal. In 2016, 95\% of the world's population was in range of at least a second-generation (2G) signal and $84 \%$ received at least a third-generation (3G) signal.

This is means that combining new infrastructures empowerment, especially in technical and telecommunication field, can really be effective in empowering the other SDG achievements, and as considered in this paper, in a sustainable and effective way. Following such an approach entities and educational systems, that would like to empower their offer, with concrete approaches to education and participation in education of the stakeholders involved in these processes.

\section{LIST OF ABBREVIATIONS}

GPRS general packet radio service GPS global positioning system

ICTs Information and Communication Technologies

LMIC Low and Middle Income Countries

LMS Learning Management Systems 
PDAs personal digital assistants

SDGs Sustainable Development Goals

MICs Middle-Income countries

SMS short messaging service

\section{ACKNOWLEDGMENTS}

The basic research of this article derives from the experience of the authors in "Aquilone" project, cofinanced by Regione Liguria, Italy, DGR 335/2012.

\section{REFERENCES}

1. Bongaarts J. World Health Organization Health in 2015: From MDGs, Millennium Development Goals, to SDGs, Sustainable Development Goals. Geneva: WHO Press; 2016.

2. No Health without a workforce: World Health Organization (WHO); 2013.

3. Bloom DE, Canning D, Chan K. Higher Education and Poverty in Sub-Saharan Africa. Vol 45: Higher Education and Poverty in Sub-Saharan Africa; 2015.

4. Iqbal S, Qureshi IA. M-learning adoption: A perspective from a developing country. The International Review of Research in Open and Distributed Learning. 2012; 13 (3):147-164.

5. Ciegis R, Ramanauskiene J, Martinkus B. The concept of sustainable development and its use for sustainability scenarios. Engineering Economics. 2015; 62 (2).

6. Preece J. Online communities: designing usability, supporting sociability. Chichester: John Wiley \& Sons; 2000.

7. Salmon G. E-activities: the key to active online learning. London: Kogan Page; 2002.

8. Hamburg I, Lindecke C, Teh Thij H. Social aspects of distance learning and blending learning methods. Proceedings of the fourth European conference on E-commerce, E-work, Distance learning, E-health, E-banking, E-business, on-line services, virtual institutes, and their influences on the economic and social environment. 2003:11-15.

9. Thurmond VA, Wambach K. Understanding interactions in distance education: a review of the literature. Journal of Instructional Technology and Distance Learning. 2004; 1:9-33.

10. Van de Walle, The impact of multiparty politics in sub Saharan Africa. Forum for Development Studies. 2001; 28(1):5-42.

11. Internet World Stats. Available at: http://www.internetworldstats.com

12 Flynn L, Jalali A, Moreau KA. Learning theory and its application to the use of social media in medical education. Postgraduate medical journal. 2015.

13 Frascio, M., Gervasoni, M., Lazzara, F., (...), Sguanci, M., Vercelli, G. New teaching models for the medical school of medicine: Comparison between oral an online classes. The experience of the Genoa school of medicine Journal of ELearning and Knowledge Society 2009 5(3), pp. 4348 .
14 Stabilini, C., Bracale, U., Pignata, G., Frascio, M. Lazzara, F., Gianetta, E. Laparoscopic bridging vs. anatomic open reconstruction for midline abdominal hernia mesh repair [LABOR]: Singleblinded, multicenter, randomized, controlled trial on long-term functional results. 2013 Trials 14(1), 357

15. Sife A, Lwoga E, Sanga C. New technologies for teaching and learning: Challenges for higher learning institutions in developing countries. International Journal of Education and Development using ICT [Online]. June 2007; 3(2).

16. Linn RL, Baker EL, Betebenner DW. Accountability systems: Implications of requirements of the no child left behind act of 2001 . Educational Researcher. 2002; 31(6):3-16.

17. Monahan T, McArdle G, Bertolotto M. Virtual reality for collaborative distance learning. Computers \& Education. 2008; 50(4):1339-1353.

18. Kay M, Santos J, Takane M. mHealth: New horizons for health through mobile technologies. World Health Organization. 2011; 64(7):66-71.

19. Ferrara E, Ponte S, Caputo E, Frascio M, Dellepiane S. Sustainable cooperative distance learning system for education in developing countries. IST-Africa Week Conference. May 2016:1-8.

20. Dellepiane S, Frascio M, Valle V, Bozano E, Ferrara E. E-learning for the medicine students of Ebolowa (Cameroon). Proceedings of the IV Congress of the University Network for Development Cooperation (CUCS). 2015.

21. Bruzzone AG, Frascio M, Longo F, Massei M, Siri A, Tremori A. MARIA: An agent driven simulation for a web based serious game devoted to renew education processes in health care. Paper presented at: International Workshop on Innovative Simulation for Health Care, 2012; Vienna (Austria).

22. The sustainable Development Goals: UN; 2017. 